\title{
URINARY INCONTINENCE FOLLOWING VAGINAL SEPTUM RESECTION IN HERLYN-WERNER-WUNDERLICH SYNDROME - A CASE REPORT
}

\author{
Slavica PONORAC ${ }^{*}$, Anamarija MEGLIČ2 ${ }^{2}$ Damjana KLJUČEVŠEK ${ }^{1}$ \\ ${ }^{1}$ Radiology department, Children's \\ Hospital University Medical Centre \\ Ljubljana, Slovenia, ${ }^{2}$ Nephrology \\ department, Children's Hospital \\ University Medical Centre Ljubljana \\ Slovenia \\ ${ }^{*}$ Corresponding author: \\ slavi.ponorac@gmail.com \\ Tel.: + 38615229264 \\ Fax.: + 38615222993 \\ Received: November 22, 2015 \\ Accepted: January 13, 2016 \\ Key words: Ectopic ureter - Uropoetic \\ anomalies $\bullet$ Genital anomaly.

\begin{abstract}
Objective - To present a case of Herlyn-Werner-Wünderlich syndrome with ectopic uropoetic remnants, diagnosed only after extensive diagnostic workup, and to stress the importance of an active search in selected cases. Case report - We present a case of an 11-year-old female who was diagnosed with Herlyn-Werner-Wunderlich syndrome and soon after resection of the hemivaginal septum began to complain of urinary incontinence. She underwent extensive diagnostic workup, including voiding cystourethrography and surgical exploration, which excluded a vesico-vaginal fistula. Urodynamic studies for urinary incontinence were normal. Correct diagnosis was achieved with magnetic resonance urography, which revealed an ectopic ureter with inserdysplastic kidney was not recognised on several abdominal ultrasound or magnetic resonance urography examinations, but was eventually confirmed with Technetium-99m dimercaptosuccinic acid renal scintigraphy, followed by single-photon emission computed tomography. Laparoscopic surgical removal of the poorly functioning ectopic remnant of the left kidney was performed. Conclusion - The close relationship between female genital and uropoetic anomalies should lead us to examine the urogenital system when a genital anomaly is identified and vice-versa. The increased awareness and availability of modern diagnostic techniques, which efficiently disclose these lesions, should prompt the correct diagnosis of these complex anomalies.
\end{abstract} \\ tion into the previously obstructed hemivagina. The ipsilateral ectopic
}

\section{Introduction}

The Herlyn-Werner-Wünderlich syndrome is a rare congenital anomaly that results from the defective fusion of the Müllerian ducts during the development of the female reproductive system $(1,2,3)$. The syndrome is characterized by uterus didelphys with obstructed hemivagina and ipsilateral renal agenesis, and has been given the acronym from obstructed hemi-vagina ipsilateral renal anomalies (OHVIRA). Malformations may remain undiagnosed during childhood and usually become symptomatic after menarche, causing obstructive symptoms. After resection of the hemivaginal septum, there is complete resolution of dysmenorrhea and no recurrence of hematometra or hematocolpos. The incidence of this malformation is estimated within the range of $0.1-3.8 \%$ respectively (1-4).

We report a case of OHVIRA syndrome with ectopic insertion of the left ureter that subtended a dysplastic kidney and was permeable with urine. 


\section{Case report}

An 11-year-old female presented with a history of severe abdominal pain that occurred shortly following menarche. The pain worsened immediately prior to menstruation and improved with menstrual flow. She denied problems with urination, nausea, vomiting or diarrhoea. Upon physical examination, the findings were nonspecific, with the exception of lower abdominal tenderness. A gynaecological examination did not show any alteration of her external genitalia. Abdominal ultrasonography (US) revealed the absence of the left kidney, compensatory hypertrophy of the right kidney, duplication of the uterus, cervix and vagina, with unilateral haematometrocolpos (Fig. 1).

A diagnosis of obstructed hemivagina with ipsilateral renal anomaly was made. Although a longitudinal vaginal septum was not directly visualised, its presence was admitted. The girl underwent resection of the hemivaginal septum, which led to complete resolution of dysmenorrhea and no recurrence of hematometra or hematocolpos. Soon after surgery she began to complain of urinary incontinence. Since she had daytime and night time urinary leakage, vaginal voiding was excluded as the possible cause. Voiding cystourethrography and thorough surgical exploration excluded a vesico-vaginal fistula. Urodynamic studies for urinary incontinence were normal. Firstly postoperative magnetic resonance imaging (MRI) confirmed uterus didelphys with normal ovaries, fallopian tubes and a solitary right kidney, without giving the explanation for urinary incontinence. Nevertheless an ectopic ureter was suspected, so magnetic resonance urography (MRU) with prolonged excretory phase was performed, that finally revealed contrast material within the remnant of the ectopic ureter which had become inserted into the previously obstructed hemivagina. The ectopic ureter continued blindly, superiorly, up to a few $\mathrm{cm}$ from the pelvic brim (Fig. 2). Renal parenchyma was not depicted by this examination, so the patient was submitted to Technetium-99m dimercaptosuccinic acid (Tc-99m DMSA) renal scintigraphy, followed by single-photon emission computed tomography (SPECT/CT), which confirmed a small $(1.5 \mathrm{~cm})$ functional renal remnant (Fig. 3). Laparoscopic surgical removal of the poorly functioning ectopic remnant of the left kidney (Fig. 4) was performed, which led to the resolution of symptoms.

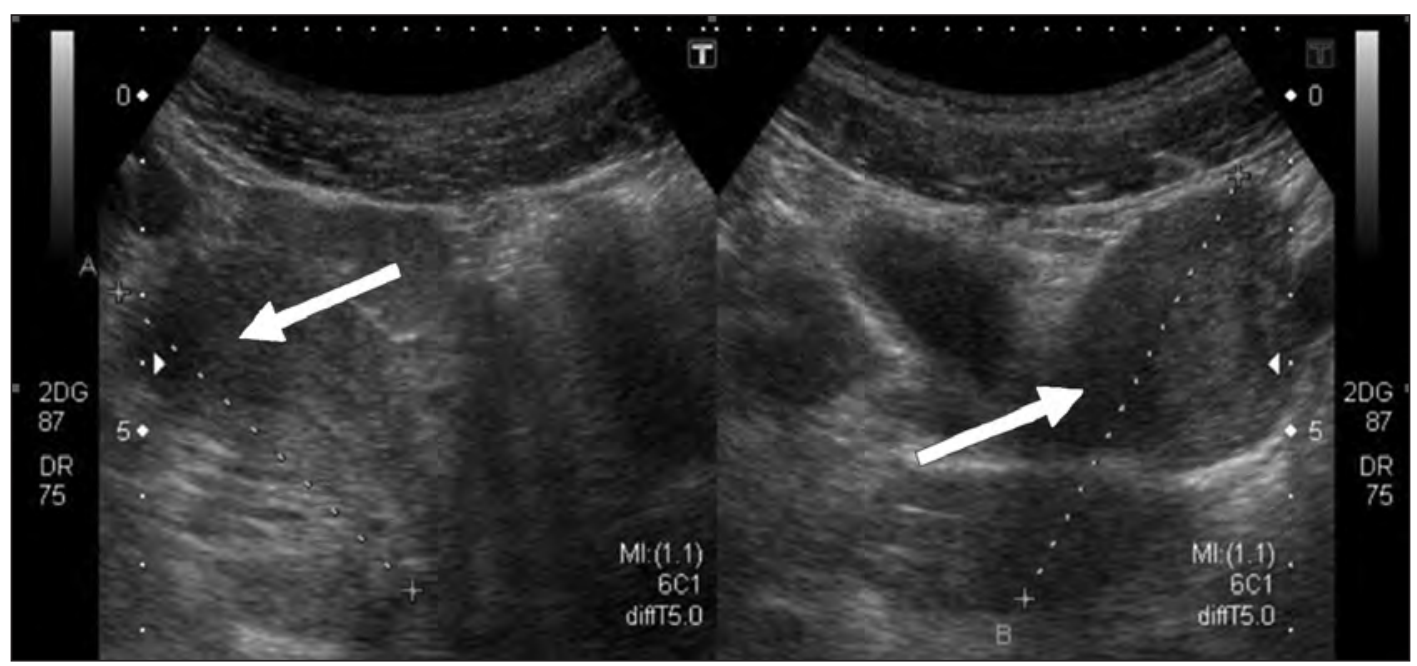

Fig. 1 An abdominal ultrasonography revealed complete duplication of the uterine horns (arrows) and cervices, with no communication between them. 


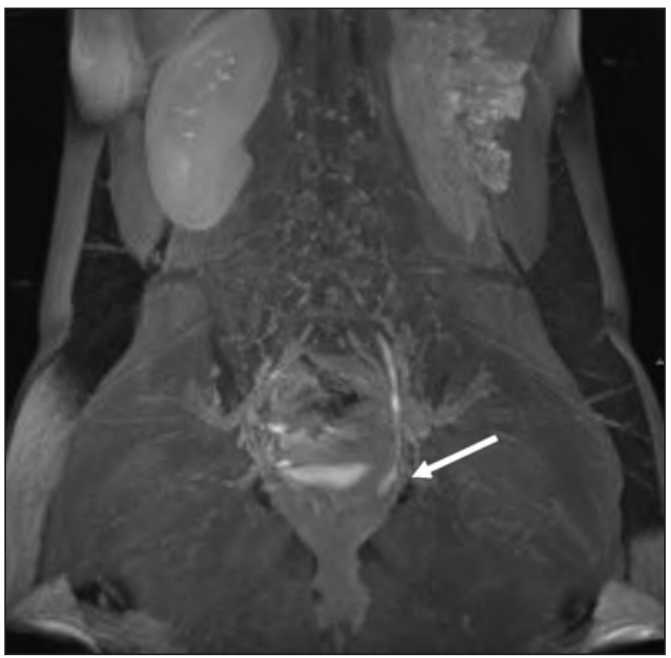

Fig. $2 M R$ urography revealed contrast material within the remnant of the ectopic ureter (arrow) which was inserted into the previously obstructed hemivagina.

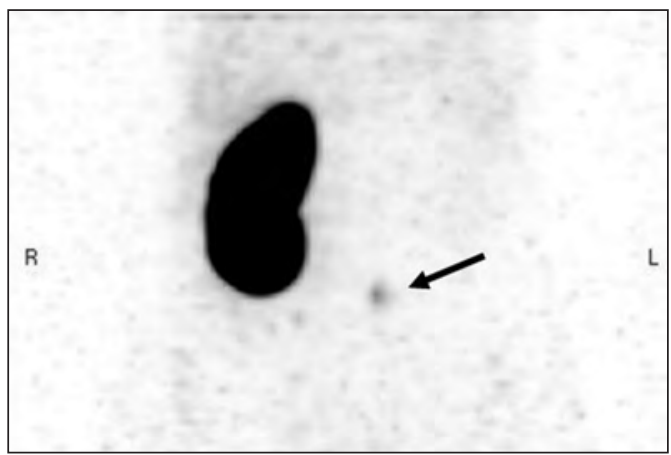

Fig. 3 Tc-99m DMSA scintigraphy followed by a SPECT/CT confirmed small functioning renal remnant (arrow).

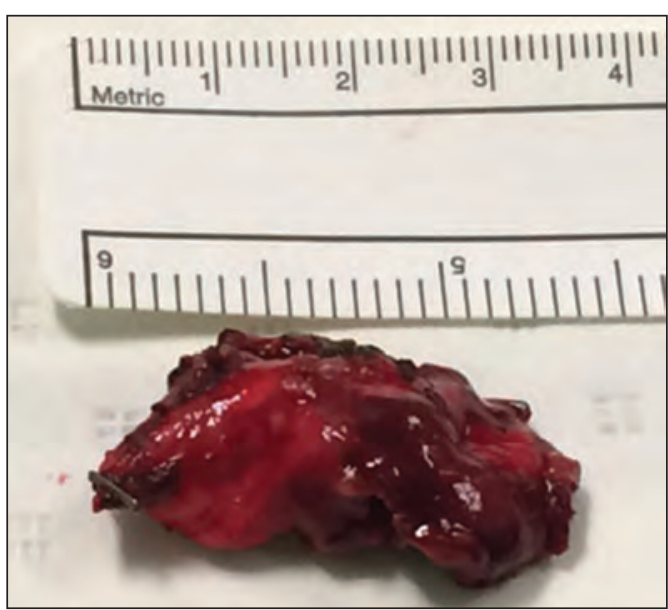

Fig. 4 Ectopic dysplastic kidney after laparoscopic removal.

\section{Discussion}

Mullerian duct anomalies (MDA) are congenital malformations of the female genital tract that result from abnormal development of the Mullerian (paramesonephric) duct derived structures. Interruption of the Mullerian duct development results in agenesis or hypoplasia of the vagina, cervix or uterus, incomplete fusion (uterus didelphys, uterus bicornuate) or reabsorption (septate uterus) (1, $2,3)$. Mesonephric ducts are not only precursors and inducers of female reproductive tract development, but also act with the Müllerian tubercle to form part of the vagina, and they play an essential role in renal development, explaining why renal tract anomalies are associated with MDA in approximately $30 \%$ of cases (4).

Several classifications of complex malformations of the female genitourinary tract are known. OHVIRA syndrome belongs to group 2.A of complex malformations of the female genital tract, or to group II.I according to Acién and Acién, or to class III according to the American Fertility Society (AFS/ ASRM) classification of Müllerian anomalies (5). This syndrome has been described with a normal, dysplastic or agenetic ipsilateral kidney, with an ectopic ureter remnant, which opens into the obstructed hemivagina. The incidence of an unilateral imperforate hemivagina associated with a single vaginal ectopic ureter is very low $(0.0064 \%)$. In the majority of published cases ureteric remnants opened in the vagina and were mostly under $10 \mathrm{~cm}$ in length. None extended more than a few centimetres above the level of the pelvic brim (6). Our findings were similar to these.

Malformations in OHVIRA syndrome may remain undiagnosed during childhood and usually become symptomatic after menarche, causing obstructive symptoms. After resection of the hemivaginal septum, there is complete resolution of dysmenorrhea and no recurrence of hematometra or hematocolpos. 
Once the hemivagina is drained, in cases of communication with an ectopic permeable ureter, urinary incontinence may appear. The ureter remnant, if not removed, may also lead to other complications, such as carcinoma and infections (7).

When a high suspicion of MDA exists, US should be performed initially to delineate any abnormalities in the genital tract. However, in order to obtain accurate MDA classification, MRI must be performed. MRU provides functional information of renal perfusion, excretion, and drainage, and combines semi-quantitative evaluation of the urinary system, with superb anatomic imaging including renal parenchyma, the pelvicalyceal system and ureter in a single test (8). In our case, MRU proved to be insufficient to delineate the supposedly functional renal parenchyma. Tc-99m DMSA scintigraphy is extremely sensitive in detecting functional renal parenchyma, but it should be combined with three dimensional imaging techniques to view the localization, as it is a planar imaging method. Gamma camera systems integrated with computed tomography give us the opportunity to have functional and anatomical imaging in the same session (9).

We want to stress the importance of an active search for ectopic uropoetic remnants in selected cases of patients with OHVIRA syndrome. It should be considered that poorly functioning, probably dysplastic, ectopic kidney parenchyma and an ectopic ureter remnant cannot be detected by conventional imaging modalities, and prolongation of magnetic resonance urography and Tc-99m DMSA scintigraphy followed by a SPECT/ CT is required.

Patients with OHVIRA syndrome may need only resection of the vaginal septum and evacuation of the haematocolpos (5). Vaginal septotomy is accomplished most commonly through a hysteroscopic approach, although laparoscopic techniques have also been de- scribed. If there is also a dysplastic, ectopic kidney with an ectopic ureter opening into the blind vagina, laparoscopic nephrectomy (guided primarily by the preoperative MRI or Tc-99m DMSA scintigraphy followed by a SPECT/CT images as in our case) and ligation of the ureter remnant may also be required (5).

\section{Conclusion}

The close relationship between female genital and uropoetic anomalies should lead us to examine the urogenital system when a genital anomaly is identified, and vice-versa. The increased awareness and availability of modern diagnostic techniques, which efficiently disclose these lesions, should prompt the correct diagnosis of these complex anomalies.

Authors' contributions: Conception and design: SP, DK; Acquisition, analysis and interpretation of data: DK, AM, SP; Drafting the article: SP, DK; Revising it critically for important intellectual content: DK, AM, SP.

Conflict of interest: The authors declare that they have no conflict of interest.

\section{References}

1. Marcal L, Nothaft MA, Coelho F, Volpato R, Iyer1 R. Müllerian duct anomalies: MR imaging. Abdom Imaging. 2011;36:756-64.

2. Roh-Eul Y, Jeong YC, Sang YK, Seung HK. A systematic approach to the magnetic resonance imaging-based differential diagnosis of congenital Müllerian duct anomalies and their mimics. Abdom Imaging. 2015;40:192-206.

3. Vilhena CJ, Metello L, Casal E, Roma F. HerlynWerner-Wunderlich syndrome: 3D ultrasonographic diagnosis in premenarche. Middle East Fertility Society Journal. 2014; 19(3):229-32.

4. Vescovo RD, Battisti S, Paola DV, Piccolo CL, Cazzato RL, Sansoni I, et al. Herlyn-Werner-Wunderlich syndrome: MRI findings, radiological guide (two cases and literature review), and differential diagnosis. BMC Medical Imaging. 2012;12:4. 
5. Acién P, Acién M. The presentation and management of complex female genital malformations. Hum Reprod Update. 2016;22(1):48-69.

6. Garge S, Bagga D, Kant SA, Kumar DY, Roshan TK, Kumar R, et al. Herlyn-Weber-Wunderlich syndrome with ectopic ureter in prepubertal female. J Indian Assoc Pediatr Surg. 2014;19(2):1035 .

7. Karaveli M, Katsanidis D, Kalaitzoglou I, Haritanti A, Sioundas A, Dimitriadis A, et al. MR urography: Anatomical and quantitative information on congenital malformations in children. Niger Med J. 2013; 54(2):136-42.

8. Wang ZJ, Daldrup-Link H, Coakley FV, Yeh BM. Ectopic ureter associated with uterine didelphys and obstructed hemivagina: preoperative diagnosis by MRI. Pediatr Radiol. 2010;40(3):358-60.

9. Poyraz NY, Özdemir E, Keskin M, and Şeyda Türkölmez. Additional Value of SPECT/CT to Tc99m MAG3 Renal Scintigraphy in the Diagnosis of a Patient with Ureteroileal Fistula. Mol Imaging Radionucl Ther. 2012;21(2):84-7. 